\title{
Impact of Faculty Development Program on Teachers' Development
}

\author{
Rajiv Mahajan $\quad$ Tejinder Singh² \\ ${ }^{1}$ Department of Pharmacology, Adesh Institute of Medical Sciences \\ and Research, Bathinda, Punjab, India \\ 2Department of Pediatrics and Medical Education, Sri Guru Ram Das \\ Institute of Medical Sciences and Research, Amritsar, Punjab, India
}

Ann Natl Acad Med Sci (India) 2021;57:247-248.

Faculty development programs (FDPs) are an important prerequisite for continuous, longitudinal professional growth of the faculty. Development refers to change in an individual over a period of time and faculty development has been referred to as "any endeavor designed to improve faculty performance in all aspects of their professional lives - as scholars, advisers, academic leaders, and contributors to institutional decisions."

Need for faculty development may be driven by institutional policies, self-perceived need, demand by the students' need, or a change in educational policies. Faculty development brings about a change in the institute while bringing in the necessary innovations, paradigm shifts and change in the curriculum, teaching, assessment and evaluation programs in any institution.

"Impact" as a term is often used in professional development literature to denote goals and achievements of a number of activities. Most evaluations of FDPs are limited to immediate vicinity of the program, including participant satisfaction, short-term gain in knowledge, application of the newly acquired skills and effects on student learning. The long-term studies of the impact have been sparse. Current perspective has been planned with an objective to highlight reported long-term effects of FDPs.

Articles were extracted by using "impact of faculty development programs," "long-term effects of faculty development programs," and "effectiveness of faculty development programs" as search keywords in PubMed and Science Direct search engines. Limitations applied were articles after 2001, English language, and free full review and research articles. Duplicates were removed, and studies with same outcome were screened and excluded. Nine articles were used for designing this perspective (-Fig. 1).

published online

June 23, 2021
DOI https://doi.org/

10.1055/s-0041-1731595 ISSN 0379-038X
Address for correspondence Rajiv Mahajan, MBBS, MD, FIMSA, FAIMER, Department of Pharmacology, Adesh Institute of Medical Sciences and Research, Bathinda, Punjab 151101, India (e-mail: drrajivmahajan01@gmail.com).

As change in the teaching practices is the most obvious and easiest to evaluate effect of FDPs, most of the research is directed toward the same. Changes in the knowledge, skills and attitudes of teachers have been reported following participation in FDPs. Some of these changes include self-reported knowledge and use of educational terms before and after participation, retrospective pre- and post-ratings of knowledge and skills, ratings of self-efficacy in teaching specific content areas, teacher behavior during group discussions, as well as behavioral changes documented using video recordings of teaching sessions. ${ }^{2}$ Other reported effects on teaching practices included reflection on current teaching, use of new teaching strategies, increase in confidence about teaching, and a more student-centered approach to teaching. ${ }^{3}$

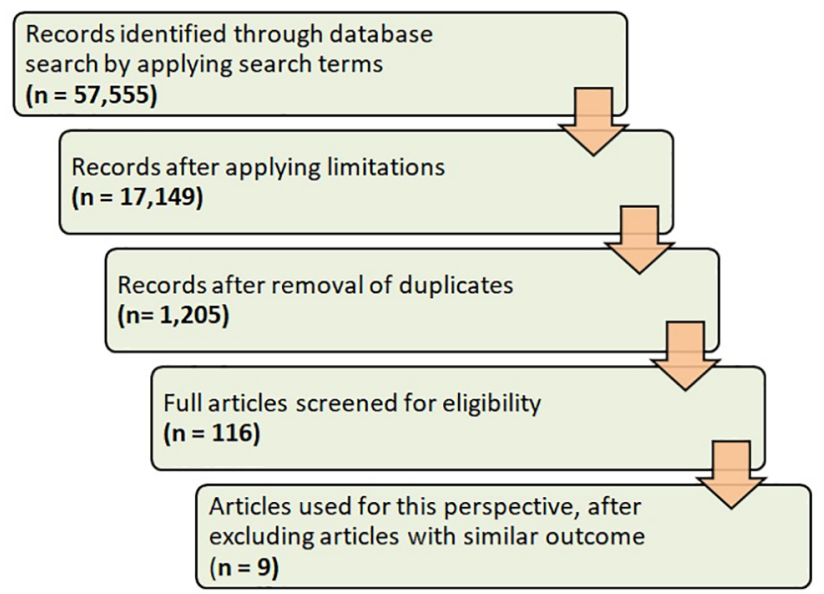

Fig. 1 Methodology for extraction and inclusion of studies.

(C) 2021. National Academy of Medical Sciences (India).

This is an open access article published by Thieme under the terms of the Creative Commons Attribution-NonDerivative-NonCommercial-License, permitting copying and reproduction so long as the original work is given appropriate credit. Contents may not be used for commercial purposes, or adapted, remixed, transformed or built upon. (https://creativecommons.org/licenses/by-nc-nd/4.0/).

Thieme Medical and Scientific Publishers Pvt. Ltd. A-12, 2nd Floor, Sector 2, Noida-201301 UP, India 


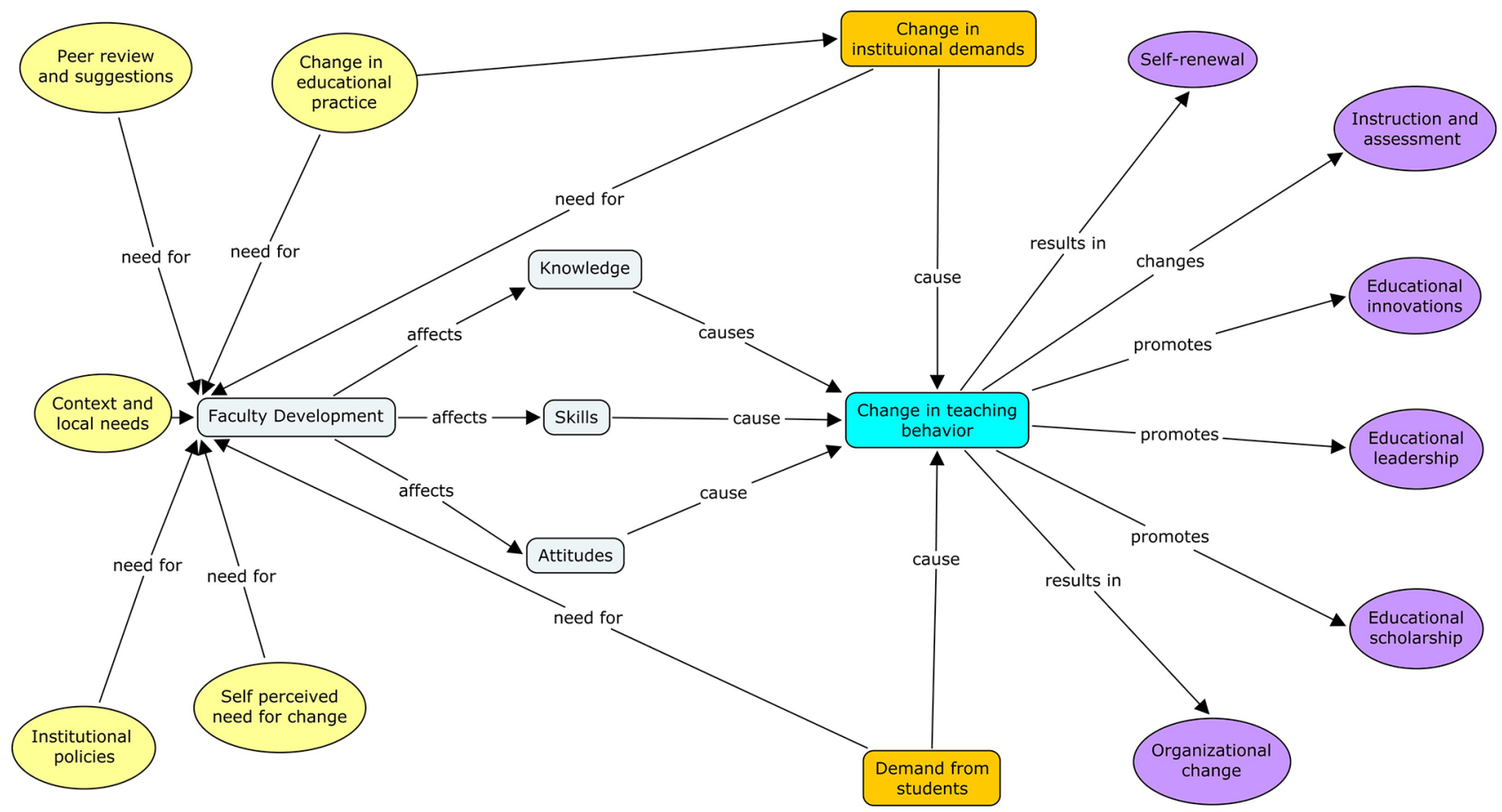

Fig. 2 Impact of faculty development programs.

Some studies have reported long-term effects ( - Fig. 2 ) like increase in publications and educational scholarships, promotions and acquiring leadership positions, selection for higher studies, and development of new curriculum. ${ }^{4}$ Changes in institutional practice like establishing new programs, influencing policy at local- and state-levels have also been reported. ${ }^{5}$ Other reported subjective impact of FDPs include transformation from "individualism to community of practice," paradigm shift to workplace-based teaching and assessment, and inculcating humanistic teaching and role modeling. ${ }^{6-8}$

Although the impact of any FDP will depend upon the intended outcomes, area of focus, methodology adopted, target audience, and availability of support system for transfer of training; all FDPs contribute significantly in enhancing faculty self-efficacy and professional competence. Effect size as significant as 0.56 to 0.73 has been reported.9,10 Its imperative to underscore that faculty development is crucial for improving the quality of education and, ultimately, the health status of the society.

\section{Conflict of Interest}

None declared.

\section{References}

1 Nelson W, Faculty who stay: Renewing our most important resource. In: Baldwin R, Blackburn R, eds. College Faculty: Versatile Human Resources in a Period of Constraint. San Francisco, CA: Jossey-Bass Publishers; 1983:67-83
2 Skeff KM, Stratos GA, Mygdal WK, et al. Clinical teaching improvement: past and future for faculty development. Fam Med 1997;29(4):252-257

3 Donnelly R. Lecturers' self-perception of change in their teaching approaches: reflections on a qualitative study. Educ Res 2008;50:207-222

4 Steinert Y, Nasmith L, McLeod PJ, Conochie L. A teaching scholars program to develop leaders in medical education. Acad Med 2003;78(2):142-149

5 Stratos GA, Katz S, Bergen MR, Hallenbeck J. Faculty development in end-of-life care: evaluation of a national train-the-trainer program. Acad Med 2006;81(11):1000-1007

6 Lee SS, Dong C, Yeo SP, Gwee MCE, Samarasekera DD. Impact of faculty development programs for positive behavioural changes among teachers: a case study. Korean J Med Educ 2018;30(1):11-22

7 Tenzin K, Dorji T, Choeda T, Pongpirul K. Impact of faculty development programme on self-efficacy, competency and attitude towards medical education in Bhutan: a mixed-methods study. BMC Med Educ 2019;19(1):468

8 Jones M, Schuer KM, Ballard JA, Taylor SA, Zephyr D, Jones MD. Outcomes of an immersive pilot faculty development program for interprofessional facilitation: a mixed methods study. J Interprof Care 2015;1:83-89

9 Bilal, Guraya SY, Chen S. The impact and effectiveness of faculty development program in fostering the faculty's knowledge, skills, and professional competence: A systematic review and meta-analysis. Saudi J Biol Sci 2019;26(4):688-697

10 Singh T, de Grave W, Ganjiwale J, Supe A, Burdick WP, van der Vleuten C. Impact of a fellowship program for faculty development on the self-efficacy beliefs of health professions teachers: a longitudinal study. Med Teach 2013;35(5):359-364 